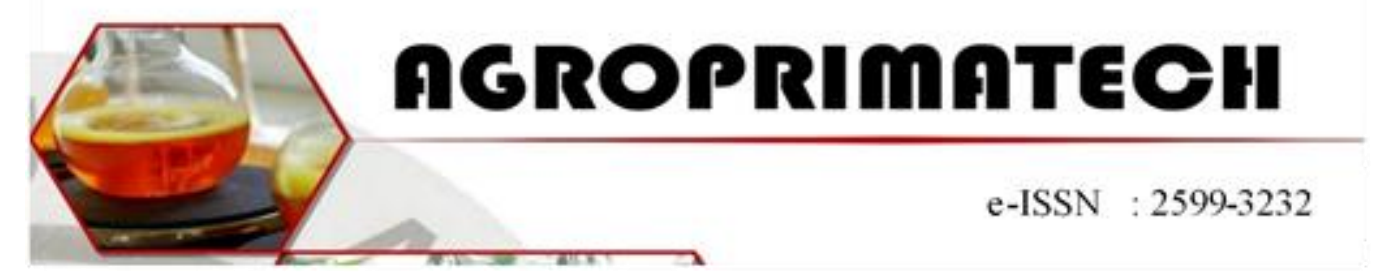

\title{
INVENTARISASI GULMA PADA PIRINGAN PERKEBUNAN KELAPA SAWIT RAKYAT TANAMAN MENGHASILKAN DI DUSUN VII, KECAMATAN AEK SONGSONGAN, ASAHAN
}

\author{
WISNU WARDHANA ${ }^{1}$ \\ ${ }^{\text {I}}$ Program Studi Agroteknologi, Fakultas Agro Teknologi, Universitas Prima Indonesia \\ Email : dhanaww50@gmail.com
}

\begin{abstract}
ABSTRAK
Tujuan dari penelitian ini adalah untuk mengetahui komposisi dan gulma yang dominan di piringan perkebunan kelapa sawit tanaman menghasilkan. Penelitian dilaksanakan di perkebunan kelapa sawit milik rakyat Dusun VII, Kecamatan Aek Songsongan, Kabupaten Asahan. Metode yang digunakan dalam penelitian ini adalah analisis vegetasi petak kuadrat dengan teknik pengambilan sampel secara purposive sampling. Jumlah plot keseluruhan sebanyak 8 plot. Hasil penelitian menunjukkan bahwa terdapat 19 total gulma yang terdiri atas, gulma berdaun lebar dengan INP tertinggi terdapat pada Adiantum trepeziforme sebesar 31,95\%, gulma berdaun sempit dengan INP tertinggi terdapat pada Axonupus compressus sebesar $18,71 \%$, dan gulma teki-tekian dengan INP tertinggi terdapat pada Cyperus difformis sebesar $10,47 \%$.
\end{abstract}

Kata Kunci : Inventarisasi, Gulma, Piringan, Perkebunan, Tanaman

\section{PENDAHULUAN}

Tanaman kelapa sawit telah banyak diusahakan oleh perkebunan negara, perkebunan rakyat maupun perkebunan besar swasta. Luas perkebunan kelapa sawit di Indonesia pada tahun 2013 seluas 10,4 juta ha dengan produksi minyak sawit sebesar 29,3 juta ton dan produktivitas kelapa sawit

mencapai $3.536 \mathrm{~kg}$ ha-1 (Direktorat Jendral Perkebunan, 2016).
Perkebunan rakyat, walaupun total luasnya mencakup sekitar $70 \%$ dari seluruh areal perkebunan di Indonesia, terdiri atas sejumlah besar kebun yang masing-masing berukuran sangat kecil. Kebun-kebun ini lahannya berstatus milik petani, dan umumnya diusahakan oleh pemilik beserta keluarganya.vUkuran kebun yang sangat kecil ini berada jauh di bawah skala ekonomi (economic of scale) sehingga menghambat pencapaian

keberhasilan usaha tani (Mangoensoekarjo dan Semangun, 2008).

Di kebun yang berukuran kecil- kecil 
ini petani memilih sendiri komoditas yang ingin mereka usahakan. Dengan demikian disuatu hamparan yang luasnya agak besar, misalnya 1.000 ha, disamping pemiliknya banyak, hamparan tersebut ditanami berbagai komoditas. Untuk tiap jenis komoditas dalam areal tersebut, lokasi tanamannya berpencaran, kebijakan pengolahannya, cara pemeliharaannya dan pengelolaan hasilnya dapat berbeda-beda. Dalam kondisi seperti ini sulit sekali mencapai efisiensi tinggi dalam upayaupaya penyediaan sarana produksi, pemeliharaan, pengumpulan hasil, pengolahan hasil, karena areal kebun campuran seluas 1.000 ha tersebut bukan areal yang kompak melainkan berselangseling dengan jenis-jenis usaha tani lainnya, pemukiman dan lain-lain (Mangoensoekarjo dan Semangun, 2008). Salah satu masalah penting dalam upaya menetapkan produksi dan menekan biaya produksi adalah masalah gulma. Hal ini selaras dengan pernyataan Pahan (2008) yang menyatakan bahwa kehadiran gulma di perkebunan kelapa sawit dapat menurunkan produksi akibat bersaing dalam pengambilan air, hara, sinar matahari, dan ruang hidup. Pada masa tanaman menghasilkan (TM), pemeliharaan tanaman kelapa sawit harus tetap dilakukan, karena mempunyai pengaruh yang besar terhadap tingkat produksi yang dicapai dengan tindakan budidaya agar memiliki respon yang baik terhadap lingkungan tempat berlangsungnya pertumbuhan. Seperti tanaman lainnya, tanaman kelapa sawit membutuhkan pengelolaan yang baik untuk mendapatkan

$$
\mathrm{KR}=\quad \begin{gathered}
\mathrm{K} \text { jenis gulma }-\mathrm{i} \\
\text { Ktotal seluruh jenis gulma }
\end{gathered}
$$$$
\text { Frekuensi (F) }
$$

$\mathrm{X} 100 \%$ keuntungan yang optimal. Pengembangan kegiatan dalam memproduksi kelapa sawit baik secara teknis maupun secara manajerial harus dilakukan secara terpadu dan selaras dengan semua subsistem yang ada didalamnya (Pardamean, 2010). Pentingnya pengendalian gulma di piringan harus dimulai dari inventarisasi gulma yang tumbuh. Kesalahan dalam pengendalian gulma dapat menyebabkan tidak efekfif dan tidak efisien bagi perusahaan perkebunan. Sukman dan Yakup (2002) menegaskan bahwa inventarisasi gulma sebelum tindakan pengendalian diperlukan untuk mengetahui jenis- jenis gulma dominan pada suatu ekosistem agar dapat diterapkan pengendalian yang efektif dan efisien. Sehingga, gulma merupakan bagian dari pengelolaan organisme pengganggu yangmerupakan komponen pokok dalam produksi pertanian.

\section{Kerapatan (K)}

Kerapatan adalah jumlah individu suatu jenis gulma pada suatu lokasi tertentu, dirumuskan : $\sum$ individu jenis

$$
\mathrm{K}=\frac{\text { gulma }}{\text { luas petak sample }}
$$

\section{Kerapatan Relatif (KR)}

Kerapatan relatif adalah persentase kerapatan suatu jenis gulma terhadap kerapatan dari seluruh jenis gulma, dirumuskan

dalam penelitian ini adalah tanaman kelapa sawit, gulma yang tumbuh di areal perkebunan kelapa sawit. Alatalat yang digunakan dalam penelitian ini adalah oven, meteran, gunting, pancang, parang, penggaris, kalkulator, alat tulis, kamera dan pisau.

Metode penelitian dilaksanakan 
dengan observasi langsung. Data yang diperoleh kemudian dianalisis dengan metode analisis vegetasi petak $\begin{array}{lllllll}\text { kuadrat } & 1 & \mathrm{~m} & \mathrm{x} & 1 & \mathrm{~m} & \text { dengan }\end{array}$ pengamatan sampel menggunakan teknik purposive sampling. Plot yang digunakan sebanyak 8 plot.

Parameter Pengamatan yaitu: Parameter yang diamati untuk inventarisasi gulma yang terdapat pada gawangan tanaman kelapa sawit menghasilkan, maka perlu dihitung Kerapatan (K), Kerapatan Relatif (KR), Frekuensi (F), Frekuensi Relatif (FR), dan Indeks Nilai Penting (INP) (Odum, 1993).
Frekuensi adalah perbandingan banyaknya suatu jenis gulma yang ditemukan pada petak-petak sampel terhadap seluruh petak sampel yang dibuat, penghitungan frekuensi setiap jenis gulma dihitung dengan rumus :

$\sum$ sub petak sampel ditemukan jenis gulma $-\mathrm{i}_{\mathrm{E}}$

\section{Frekuensi Relatif (FR)}

Frekuensi relatif adalah persentase frekuensi suatu jenis gulma terhadap frekuensi seluruh jenis gulma, dirumuskan :

$$
\mathrm{FR}=\frac{\mathrm{F} \text { jenis gulma }-\mathrm{i}}{\mathrm{F} \text { total seluruh jenis gulma }} \times 100 \%
$$

Indeks Nilai Penting (INP)

Indeks nilai penting merupakan hasil penjumlahan nilai relatif kedua parameter (kerapatan dan frekuensi) yang telah diukur sebelumnya, sehingga nilainya juga bervariasi, dirumuskan :

INP = Kerapatan Relatif + Frekuensi Relatif

HASIL DAN PEMBAHASAN

\section{Hasil Analisis Vegetasi gulma}

Hasil analisis vegetasi yang dilakukan pada saat inventarisasi gulma di areal perkebunan kelapa sawit rakyat terdapat 19 spesies gulma yang dibedakan atas gulma 
berdaun lebar, berdaun sempit dan teki-tekian.

Tabel 1. Hasil pengamatan analisis vegetasi tanaman

\begin{tabular}{clcccccc}
\hline No & Spesies gulma & Total & K $\left(\mathrm{ind} / \mathrm{m}^{2}\right)$ & $\mathrm{KR}(\%)$ & $\mathrm{F}$ & FR (\%) & INP (\%) \\
\hline & Berdaun Lebar & & & & & & \\
2 & Adiantum trapeziforme & 233 & 29,13 & 29,38 & 0,13 & 2,56 & 31,95 \\
3 & Alocacia cypeolata & 7 & 0,88 & 0,88 & 0,38 & 7,69 & 8,58 \\
4 & Asystasia intrusa & 15 & 1,88 & 1,89 & 0,38 & 7,69 & 9,58 \\
5 & Caladium tricolor & 2 & 0,25 & 0,25 & 0,13 & 2,56 & 2,82 \\
6 & Clidemia hirta & 9 & 1,13 & 1,13 & 0,38 & 7,69 & 8,83 \\
7 & Malestoma affine & 137 & 17,13 & 17,28 & 0,38 & 7,69 & 24,97 \\
8 & Selaginella kraussiana & 14 & 1,13 & 1,13 & 0,38 & 7,69 & 8,83 \\
9 & Sida rhombifolia & 9 & 1,13 & 1,77 & 0,13 & 2,56 & 4,33 \\
10 & Spermacoce ocymoides & 3 & 0,38 & 1,13 & 0,38 & 7,69 & 8,83 \\
11 & Urena lobate & 3 & 0,38 & 0,38 & 0,13 & 2,56 & 2,94 \\
\hline & Berdaun Sempit & & & & & & \\
1 & Axonopus compressus & 128 & 16,00 & 16,14 & 0,13 & 2,56 & 18,71 \\
2 & Botrychium ternatum & 18 & 2,25 & 2,27 & 0,13 & 2,56 & 4,83 \\
3 & Imperata cylindrica & 11 & 1,38 & 1,39 & 0,13 & 2,56 & 3,95 \\
4 & Ottochloa nodosa & 112 & 14,00 & 14,12 & 0,13 & 2,56 & 16,69 \\
5 & Paspalum conjugatum & 16 & 2,00 & 2,02 & 0,38 & 7,69 & 9,71 \\
\hline & Teki-tekian & & & & & & \\
1 & Cyperus difformis & 22 & 2,75 & 2,77 & 0,38 & 7,69 & 10,47 \\
2 & Cyperus kyllingia & 15 & 1,88 & 1,89 & 0,38 & 7,69 & 9,58 \\
3 & Cyperus rotundus & 30 & 3,75 & 3,78 & 0,13 & 2,56 & 6,35 \\
\hline & Jumlah & 753 & 99,13 & 100 & 4,88 & 100 & 200 \\
\hline
\end{tabular}

Keterangan : K = Kerapatan ; KR = Kerapatan Relatif ; F = Frekuensi ; FR = Frekuensi Relatif ; dan INP = Indeks Nilai Penting.

Berdasarkan tabel di atas dapat diketahui pada gulma berdaun lebar dominansi paling tinggi terdapat pada gulma Adiantum trapeziforme 31,95 $\%$, pada gulma berdaun sempit dominansi paling tinggi terdapat pada gulma Axonopus compressus 18,71 $\%$. Sedangkan pada gulma teki-tekian dominansi paling tinggi terdapat pada gulma Cyperus difformis $10,47 \%$.

\section{Gulma Berdaun Lebar}

Berdasarkan hasil penelitian pada Tabel 1 dapat diketahui bahwa gulma berdaun lebar terdapat 11 (sebelas) jenis dan INP yang tertinggi terdapat pada gulma Adiantum trapeziforme memiliki INP sebesar 31,95\%. Gulma ini mengandung suatu gologan senyawa alkaloid dan golongan senyawa fenolik yaitu senyawa flovanoid. Tumbuhan ini memiliki akar serabut, batangnya yang khas dengan warna hitam mingkilat dan daunnya tidak berbentuk memanjang tetapi cenderung membulat. Tumbuhan ini termasuk tumbuhan paku-pakuan. Pada umumnya hidup di atas tanah dengan cara bergerombol dan mempunyai akar serabut yang ujung akarnya dilindungi, Kebanyakan hidup di tempat-tempat yang terlindung. Sedangkan jenis suplir lainnya ada yang dapat hidup di lingkungan yang agak terbuka tumbuhan ini Berkembang biak dengan spora. Penyebaran tumbuhan ini dilakukan melalui spora yang terdapat di dalam kotak sporangium. Organ ini sangat efisien untuk kepentingan penyebaran 
karena dapat mencapaitempat-tempat yang jauh dengan bantuan angin, serta dapat diproduksi dengan jumlah yang banyak. Dengan cara demikian sebagian dari spora tersebut dapat menemukan tempat yang cocokuntuk pertumbuhannya. Spora merupakan salah satu penentu penamaan jenis tumbuhan paku. Spora merupakan tahap perkembangbiakan generatif tumbuhan paku (Raven et al., 1992).

\section{Gulma Berdaun Sempit}

Gulma berdaun sempit terdapat 5 (lima) jenis gulma dan INP yang tertinggi terdapat pada gulma Axonopus compressus atau yang dikenal dengan nama lokal rumput paitan memiliki INP sebesar 18,71\%. Rumput paitan ini memiliki sistem perakaran tunggang. Akarnya memiliki panyak percabangan, berwarna coklat keputih-putihan. bentuknya tertekan ke arah lateral sehingga agak pipih, tidak berbulu, tumbuh tegak berumpun. Daunnya pada bagian pangkal meluas dan lengkung, ujungnya agak tumpul, permukaan sebelah atas ditumbuhi bulu-bulu halus, ukuran panjangnya 2,5-37,5 cm dan ukuran lebar 6-16 $\mathrm{mm}$. Bunganya terdiri dari dua sampai tiga tangkai yang ramping, tangkai perbungaan tidak berbulu, pada bagian ujung (apex) terbentuk dua cabang bunga atau bulir (spica) yang berhadapan berbentuk huruf V. Buahnya tidak saling tumpang tindih, berwarna hijau muda dan berukuran kecil. Biji berbentuk sangat kecil, berwarna putih atau memiliki warna putih kehijau-hijauan. Menurut Munandar dan Hardosuwignyo (1990), rumput paitan atau rumput karpet berasal dari India dan Amerika Tengah bagian selatan. Rumput ini merupakan rumput daerah tropis yang dapat beradaptasi dengan kekeringan. Rumput paitan memiliki lebar helai daun berkisar $4-8 \mathrm{~mm}$, tidak berbulu atau berbulu jarang pada pangkal daun. Rumput Paitan dapat membentuk hamparan yang lebat dengan warna hijau muda. Sistem perakarannya lebat tetapi dangkal. Rumput Paitan dapat tumbuh pada $\mathrm{pH}$ tanah $4,5-5,5$.

\section{Gulma Teki}

Gulma teki hanya terdapat tiga (tiga) jenis gulma dan INP yang tertinggi terdapat pada gulma Cyperus difformis memiliki jumlah dominansi 10,47 \%. Gulma ini mengandung suatu gologan senyawa fenol yang dapat menghambat pertumbuhan tanaman. Berakar serabut, batang bertekstur lembut dengan tinggi mencapai $30 \mathrm{~cm}$, daun yang memanjang dari pangkal tanamandan bunga bundar selebar satu sampai tiga sentimeter,berisi hingga 120 kelopak, masing-masing panjang dan sebagian atau seluruhnya tertutup hingga 30 bunga. Gulma ini masuk dalam daftar gulma terburuk di dunia, menjadi masalah terutama pada padi, tebu, teh dan jagung. Ini adalah gulma dominan pada benih padi langsung ketika terjadi pada kepadatan tanaman yang tinggi, membentuk sepetak lebat vegetasi pada tanaman muda dan dapat menyebabkan hilangnya hasil padi $12-50 \%$. Berasal dari daerah tropis, tetapi menyebar dengan baik di luar daerah asalnya. Ini memiliki periode generasi yang relatif singkat hanya 4 hingga 6 minggu dari biji ke benih. Ini dapat menyebar di sepanjang aliran air dan tumbuh di lokasi yang terganggu, tepi danau dan tepi sungai (Sukman dan Yakup, 2002). 


\section{KESIMPULAN DAN SARAN}

\section{Kesimpulan}

Bedasarkan hasil penelitian yang dilakukan mengenai inventarisasi gulma pada piringan perkebunan kelapa sawit rakyat tanaman mengahasilkan dapat disimpulkan bahwa, pada lahan kelapa sawit milik rakyat terdapat 19 jenis gulma, yang terdiri dari 11 gulma berdaun lebar dengan INP tertinggi terdapat pada gulma Adiantum trapeziforme dengan $31,95 \%$, gulma berdaun sempit berjumlah 5 dengan INP tertinggi pada gulma Axonupus compressus sebesar $18,71 \%$, dan gulma teki tekian berjumlah 3 dengan INP tertinggi terdapat pada gulma Cyperus difformis sebesar 10,47\%.

\section{Saran}

Disarankan kepada pemilik kebun untuk mengendalikan gulma dengan menggaruk dan mendongkel piringan, agar gulmanya mati sampai ke perakarannya. Rotasi pengendalian juga harus lebih sering dilakukan, sehingga dapat mengurangi pertumbuhan gulma tersebut.

\section{DAFTAR PUSTAKA}

As, M. 2005. Keanekaragaman dan Potensi Tumbuhan Paku (Pteridophyta) di Hutan Desa Lampeapi Kecamatan Wawonii Barat Kabupaten Konawi. Skripsi. Fakultas Matematika dan Ilmu Pengetahuan Alam. Universitas Haluoleo. Kendari.

Anderson, W.P. 2007. Weed Science : Principles and Aplications.
Third Edisi. Waveland Press Inc. United States of America. 59.

Barus. 2003. Pengendalian Gulma Di Perkebunan, Efektifitas dan Efisiensi Aplikasi Herbisida. Yogyakarta : Kanisius (Anggota IKAPI).

Caton, B. P., Mortimer M., Hill, J. E. dan Johnson, D. E. 2011. Panduan Lapang Praktis Gulma Padi di Asia. Edisi kedua. Diterjemahkan oleh: Diah Wurjandari, Entis Sutisna dan Zulkifli Zaini. Priscilla Grace Canas-IRRI. Filipina.

Dalimarta, S. 2003. Atlas tumbuhan Obat Indonesia Jilid 3. Puspa Swara. Jakarta.

Damaru. 2011. Alang-alang. Makalah Ekologi Tumbuhan. Universitas Sumatera Utara. Medan.

Direktorat Jenderal Perkebunan. 2016. Statistik Kelapa Sawit Indonesia 2014-2016. [Internet] [diunduh 2 September 2018].

Djojosumarto, P., 2000. Teknik Aplikasi Pestisida Pertanian. Yogyakarta : Kansius.

Ersyad, Z., Ardian dan Silvina F. 2017. Inventarisasi gulma dan seedbank pada tanaman kelapa sawit (Elaeis guineensis Jacq.) menghasilkan di kebun Sei Galuh PT. Perkebunan Nusantara V Kampar Riau. 
JOM FAPERTA. Vol. 4:2. Riau.

Fauzi, Y. Yustina E,W. Imam S. dan Rudi H 2014. Budidaya, Pemanfaatan Hasil dan Limbah, Analisis Usaha dan Pemasaran Kelapa Sawit. Jakarta : Penebar Swadaya.

Francis, J.K. 2004. Clidemia hirta (L.) D. Don. Departement of Agriculture. Puerto Rico.

Halloran, G. M. 1978. Breeding self pollinated crops. In Halloran, G.M., R.Knight, K.S.

McWhirter and D.H.B. Sparrow, 1979. A course Manual in Plant Breeding. AAUCS. Brisbane.

Holm, G. 1977. The World's Worst Weeds. Published for The East-West Center by The University Press of Hawaii. Honolulu.

Jusfah, J. 1984. Tumbuh- Tumbuhan Penganggu dan Pengendaliannya. Padang : Universitas Andalas.

Kiswanto, J.H., Purwanta, B. Wijayanto. 2008. Teknologi Budidaya Kelapa Sawit. Balai Besar Pengkajian dan Pengembangan Teknologi Pertanian, Badan Penelitian dan Pengembangan Pertanian, http://cybex.deptan.go.id [5 September 2018].

Kristanto, B.A., 2006, Perubahan karakter tanaman jagung (Zea mays L.) akibat alelopati dan persaingan teki (Cyperus rotundus L.). Jurnal
Indonesia Tropica Animal Agriculture, Vol. 31, no. 2.

Lubis, A. 2000. Kelapa Sawit (Elaeis guineensis Jacq.) : Teknik Budidaya Tanaman. Sinar. Medan.

Mangoensoekarjo S dan $\mathrm{H}$. Semangun. 2005. Manajemen Agribisnis Kelapa Sawit. Yogyakarta : Gadjah Mada University Press.

Munandir, J. 2010. Ilmu Gulma. Malang : Universitas Brawijaya Press (UB Press).

Munandar, A dan S. Hardjosuwignyo. 1990. Rumput Lansekap. Bogor : Institut Pertanian Bogor.

Nooteboom dan Stevens. 2000. Cyperus kyllingia. http://portal.cybertaxonomy. org/floramalesiana/cdm_data portal/taxon/8eaf98367a9b49 a28c1e061395a4ff39. Diakses pada 2 September 2018 pukul 15.12 WIB.

Odum, E.P. 1993. Fundamental Ecology 3rd. W.B. Sauders Co. Philadelphia.

Pahan, 1. 2008. Panduan Lengkap Kelapa Sawit: Manajemen Agribisnis dari Hulu Hingga Hilir. Jakarta: Penebar Swadaya.

Pahan, I. 2015. Panduan Teknis Budi Daya Kelapa Sawit Untuk Praktisi Perkebunan. Penebar Swadaya. Bogor.

Pardamean, Maruli. 2010. Panduan Lengkap Pengelolaan Kebun 
dan Pabrik Kelapa Sawit. Jakarta : Cetakan Pertama. PT. Agro Media Pustaka.

Purba, P., E.S. Sutarta, M.L. Fadli, A.D. Koedadiri, S. Rahutomo, dan A.Sutanto. 2005. Pemeliharaan tanaman kelapa sawit belum menghasilkan. Pusat Penelitian Kelapa Sawit. Medan. Raven, P.H., R.F. Evert dan S.E. Eicrth Phhorn. 1992. Biolgy of Plants. Worth Publiser. New York.

Sebayang, H.T. 2008. Pidato Pengkukuhan: Gulma dan pengendaliannya dalam upaya peningkatan produksi tanaman.

http://www.brawijaya.ac.id.

Diakses tanggal 4 September 2018.

Sembodo, D.R.J. 2010. Gulma dan Pengelolaannya. Yogyakarta : Graha Ilmu.

Soedarsan, A Rifai. 1975. Gulma di Perkebunan. Jawa Timur : Gabungan Perusahaan Perkebunan.

Sukman, Yernelis dan Yakup. 2002. Gulma dan Teknik Pengendaliannya. Jakarta :PT Raja Garafindo Persada.

Suwarto., S. Herawati, dan Y. Octavianty . 2014. Top 15 Tanaman Perkebunan. Jakarta : Penebar Swadaya.

Syahputra, E., Sarbino, dan S. Dian. 2011. Weed assesment di perkebunan kelapa sawit lahan gambut. Jurnal Perkebunan dan Lahan Tropika.
Tamasouw, Ino. Menanam dan Merawat Keladi Hias dan Kerabatnya. Depok : Agro Media Pustaka.

Tjitrosoedirdjo, S., I. H. Utomo dan J. Wiroatmodjo. 1984. Pengelolaan gulma di perkebunan. Jakarta : Gramedia.

Tjitrosoepomo, G. 2004. Taksonomi Tumbuhan (Spermatophyta). Cetakan ke delapan. UGM Press.

Tjitrosoepomo, Gembong. 2005. Morfologi Tumbuhan. Yogyakarta : Universitas Gajah Mada Press.

Tjitrosoepomo, G. 2009. Taksonomi Tumbuhan Schizophyta, Thallophyta, Bryophyta, Pteridophyta. Yogyakarta : Gadjah Mada University Press.

Tjokrowardojo, AS., Djauhariya, Endojo. 2011. Gulma dan Pengendaliannya pada Budidaya Tanaman Nilam. Bogor : Balai Penelitian Tanaman Obat dan Aromatik.

Yakup dan S. Yarnelis. 2002. Gulma dan Teknik Pengendaliannya. Jakarta : PT. Raja Grafindo Persada.

Yuniarti. 2011. Inventaris dan karakter morfologi tanaman durian

(Durio zibthinus Murr) di kabupaten tanah datar. Skripsi FMIPA Biologi. Universitas Sriwijaya 
